\title{
Comparison of GeneXpert MTB/RIF Assay in Broncho Alveolar Lavage and Gastric Lavage Samples
}

\author{
Ravi Mahat, Nadeem Rizvi, Nausheen Saifullah, Madiha Tawfik, Ashok Kumar \\ Department of Chest Medicine, Jinnah Postgraduate Medical Centre, Karachi, Pakistan \\ Email: ravi.mahat@gmail.com,rizvi_n@hotmail.com,drnausheenahmad@hotmail.com, \\ madihabawer@hotmail.com, ashoka_pj@yahoo.com
}

Received 27 June 2016; accepted 2 September 2016; published 5 September 2016

Copyright (C) 2016 by authors and Scientific Research Publishing Inc.

This work is licensed under the Creative Commons Attribution International License (CC BY). http://creativecommons.org/licenses/by/4.0/

(c) (i) Open Access

\begin{abstract}
Objective: To compare the yield from Gastric lavage (GL) and Broncho alveolar lavage (BAL) samples in adult patients suspected case of Tuberculosis but not producing sputum. Methodology: 80 adults with suspected case of tuberculosis but not producing sputum were recruited. 72 patients were then subjected to one gastric lavage followed by Broncho-alveolar lavage in the same morning. The collected samples were subjected to GeneXpert MTB/RIF assay. Result: Of the 72 patients samples, the mean age was 38.6 years. $41(56.9 \%)$ were male and $31(43.1 \%)$ were female. History of TB contact was present in $25(34.7 \%)$ patients. $37(51.4 \%)$ patients had GeneXpert MTB/RIF positive on BAL and/or GL samples. The GeneXpert MTB/RIF of BAL fluid was positive on 35 (48.6\%), which was not significantly greater than that for specimens from GL, which was 28 (38.9\%) ( $p$ > 0.05). In $26(36.1 \%)$ cases, GeneXpert MTB/RIF was positive in both BAL and GL samples. Conclusion: This study showed the yield of GeneXpert MTB/RIF in GL was comparable to BAL to detect Mycobacterium tuberculosis complex. Patients who can't produce sputum, GL can be a good alternative to BAL to detect Mycobacterium tuberculosis complex in resource poor areas and patients who do not tolerate Bronchoscopy.
\end{abstract}

\section{Keywords}

Mycobacterium tuberculosis Complex, Rifampicin Resistance, Bronchoscopy, TB Suspects

\section{Introduction}

Tuberculosis (TB) is one of the most common communicable diseases affecting all age groups in low-income

How to cite this paper: Mahat, R., Rizvi, N., Saifullah, N., Tawfik, M. and Kumar, A. (2016) Comparison of GeneXpert MTB/RIF Assay in Broncho Alveolar Lavage and Gastric Lavage Samples. Advances in Infectious Diseases, 6, 107-112.

http://dx.doi.org/10.4236/aid.2016.63014 
countries. Although TB is preventable and treatable in most cases, according to the WHO Global Report 2014, approximately 9.0 million people developed TB in 2013 amongst which 1.5 million died from it [1]. It ranks as the second leading cause of death from an infectious disease worldwide, after the human immunodeficiency virus (HIV). Diagnosis of pulmonary TB in individuals is through clinical presentation, sputum test and bacteriological confirmation in laboratories. These diagnostic tests range from traditional smear microscopy, culture to newer rapid tests like GeneXpert MTB/RIF and line probe assay.

The GeneXpert MTB/RIF is an automated cartridge based nucleic acid amplification test that detects $\mathrm{Myco-}$ bacterial tuberculosis complex DNA and also the bacterial resistance to Rifampicin. It is a rapid screening tool feasible for use in conventional laboratories and requires minimal training. Since it detects Rifampicin resistance, patients can be put on further evaluation of drug resistant TB. Aiming at the rpoB, it helps to deal with all mutations found in more than $99.5 \%$ of all rifampicin resistant strains [2]. It does not show cross reactivity to nontuberculous mycobacteria. According to a systematic review, GeneXpert attained a pooled sensitivity of $88 \%$ and pooled specificity of $98 \%$ when used instead of smear microscopy as an initial diagnostic test [3]. In smear positive, culture positive cases pooled sensitivity was found to be $98 \%$, in smear negative cases it was $68 \%$ and $80 \%$ in HIV patients. It is also useful in patients who are smear negative cases of presumptive TB. In adults and children suspected of HIV associated TB or MDR TB, it should be used as an initial diagnostic test [1].

In December 2010, GeneXpert MTB/RIF assay was endorsed by WHO and then recommended for detection of Mycobacterium tuberculosis complex and rifampicin resistance. Overall, the sputum GeneXpert MTB/RIF assay has similar sensitivity, specificity and accuracy as culture on solid media for Mycobacteria [4].

In everyday clinical practice, we often encounter patients suspected of pulmonary tuberculosis but they do not produce sputum. One study showed $50 \%$ of patients with suspected active TB are either unable to produce sputum or demonstrate a negative sputum smear for acid fast bacillus (AFB) [5]. In such situations sampling through BAL, induced sputum (IS) and GL are alternatives. Where available, bronchoscopy and BAL can be performed to obtain samples. However, it requires special facilities, trained staff and is not accessible in limited-resource settings. Additionally, due to its invasive nature many patients may not prefer and tolerate it [6]. Although yield of induced sputum has favorable results, its use requires isolation rooms with negative pressure, which may not be available in many health care settings [6] [7]. The GL method is preferred in diagnosis of TB in children who swallow their sputum and cannot expectorate. Many studies have shown good result of GL for AFB smear and culture [6] [7]. In the centers where WHO has provided GeneXpert machine is available, it is possible to make bacteriological diagnosis within 2 hours. As the prevalence of MDR TB is increasing, this test also helps to detect Rifampicin resistance in suspected cases and guide further management.

Therefore, in order to confirm the clinical and radiological findings in patients with suspected active TB who are not able to produce sputum samples, GL and BAL were performed to obtain specimens for bacteriologic confirmation. In this study, comparison of the yield of GL and BAL in terms of GeneXpert MTB/RIF result was made.

\section{Methods}

A prospective study was conducted in the Department of Chest Medicine of Jinnah Postgraduate Medical Centre, Karachi, Pakistan. The institutional ethics committee approved the study, and written informed consent was taken from each participant. Patients were recruited from outpatient clinics of tertiary care center from March 2014 to December 2014.

The patients were not producing sputum included in the study if they met following inclusion criteria:

- $\quad$ TB Suspects, who had respiratory and/or constitutional symptoms for more than 2 weeks as defined by WHO.

- $\quad$ Chest radiography suggestive of active TB.

- $\quad$ Patients more than 15 years of age of both gender.

- $\quad$ No previous history of tuberculosis.

Patients were excluded from the study if they had:

- Previous history of tuberculosis or anti-tubercular therapy.

- History of structural lung disease like COPD, bronchiectasis, diffuse parenchymal lung disease.

- $\quad$ Patients who are too breathless or hypoxic to undergo the procedure.

GL: After explaining details regarding the procedure, patients were admitted one day prior to the test. After overnight fast, Gastric lavage (GL) specimens were obtained in the morning. This technique involves inserting a 
appropriate size nasogastric tube into the stomach of the patient, rinsing the stomach with $\sim 50 \mathrm{~mL}$ of sterile normal saline, and aspirating the stomach contents. The procedure yielded volumes of 20 - $40 \mathrm{ml}$ GL specimens. The sample was collected in a sterile syringe.

BAL. Fiber-optic bronchoscopy was performed on fasting patients after gastric lavage in the same morning. Local anesthesia and sedation were administered. After the bronchial tree was inspected, $60-100 \mathrm{~mL}$ of normal saline was instilled and aspirated from lung segments involved by the disease process, as indicated by a chest radiograph. Approximately, 20 - $30 \mathrm{~mL}$ of BAL fluid was obtained. BAL and GL samples were transported within 20 - 30 min to the GeneXpert laboratory. Patients were discharged once they were stable enough after the procedures, and were advised to follow up in OPD with reports.

Data on age, sex, history of TB contact and report of GeneXpert MTB/RIF for both specimens was collected on a data entry form. Data analysis was performed in SPSS window version 19 software.

\section{Results}

Total 80 cases of suspected pulmonary tuberculosis not producing sputum were recruited for the study. 5 patients declined to undergo bronchoscopy, one refused GL later on and two patients did not tolerate bronchoscopy. Complete specimens were obtained from 72 patients. Out of these 41 (56.9\%) were male, and 31 (43.1\%) were female (Figure 1). The Mean age was $38.6 \pm 18.3$ (16 to 72 years) and 25 (34.7\%) had TB contact history (Table 1).

Total 37 (51.4\%) patients had GeneXpert MTB/RIF positive on either BAL and/or GL samples. In BAL fluid sample, MTB complex was detected by GeneXpert MTB/RIF in 35 (48.6\%) patients and negative in 37(51.4\%). In GL fluid samples MTB complex was detected in 28 patients (38.9\%) and negative in $44(62.1 \%)(\mathrm{p}>0.05)$ (Table 2). In 26 (36.1\%) patients, both BAL and GL samples were positive (Figure 2). In 2 (2.7\%) patients, only GL was positive and BAL was negative. Primary rifampin resistance was detected in 3 (4.1\%) patients and they were subjected for further evaluation of drug resistance tuberculosis.

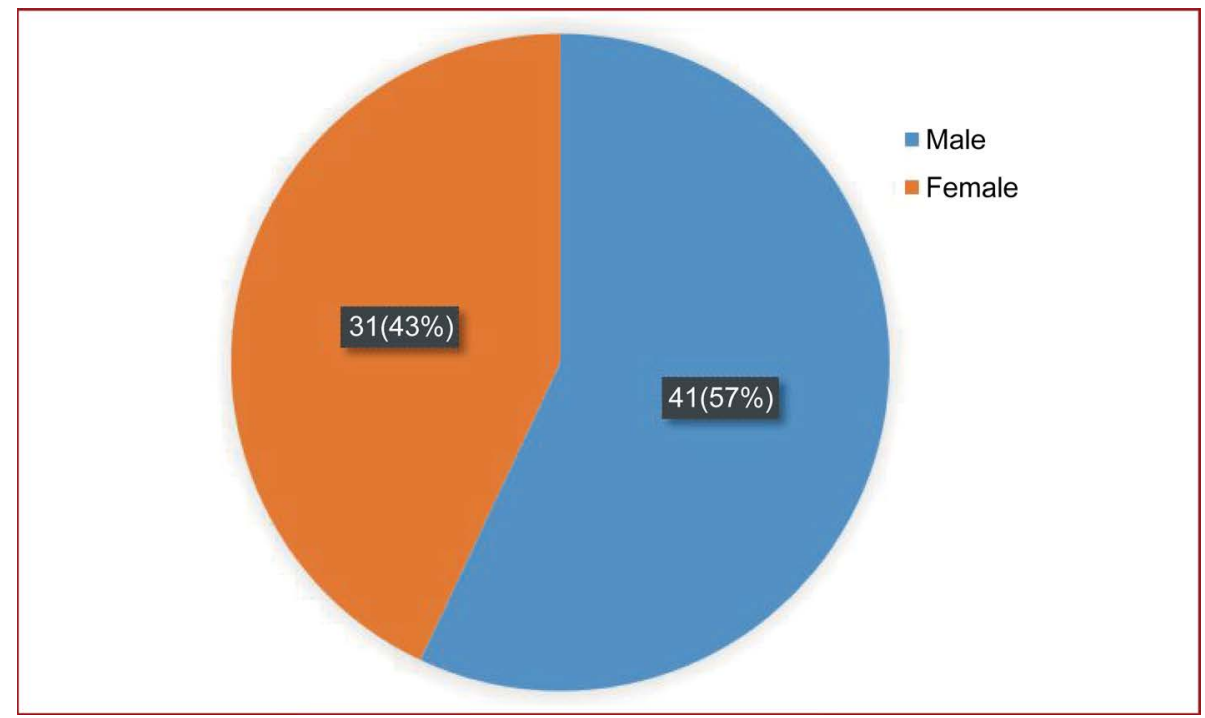

Figure 1. Gender distribution.

Table 1. Baseline characteristics of the patients.

\begin{tabular}{cc}
\hline Gender & \\
\hline Male-No. (\%) & $41(56.9)$ \\
Female-No. (\%) & $31(43.1)$ \\
Age (mean) & $38.6 \pm 18.3$ years \\
TB contact history-No. (\%) & $25(34.7)$ \\
\hline
\end{tabular}

*Plus-minus values are means \pm SD. 
Table 2. Result of GeneXpert in BAL and GL samples.

\begin{tabular}{ccc}
\hline & Positive n (\%) & Negative n (\%) \\
\hline BAL & $35(48.6 \%)$ & $37(51.4 \%)$ \\
GL & $28(38.9 \%)$ & $44(61.1 \%)$ \\
\hline
\end{tabular}

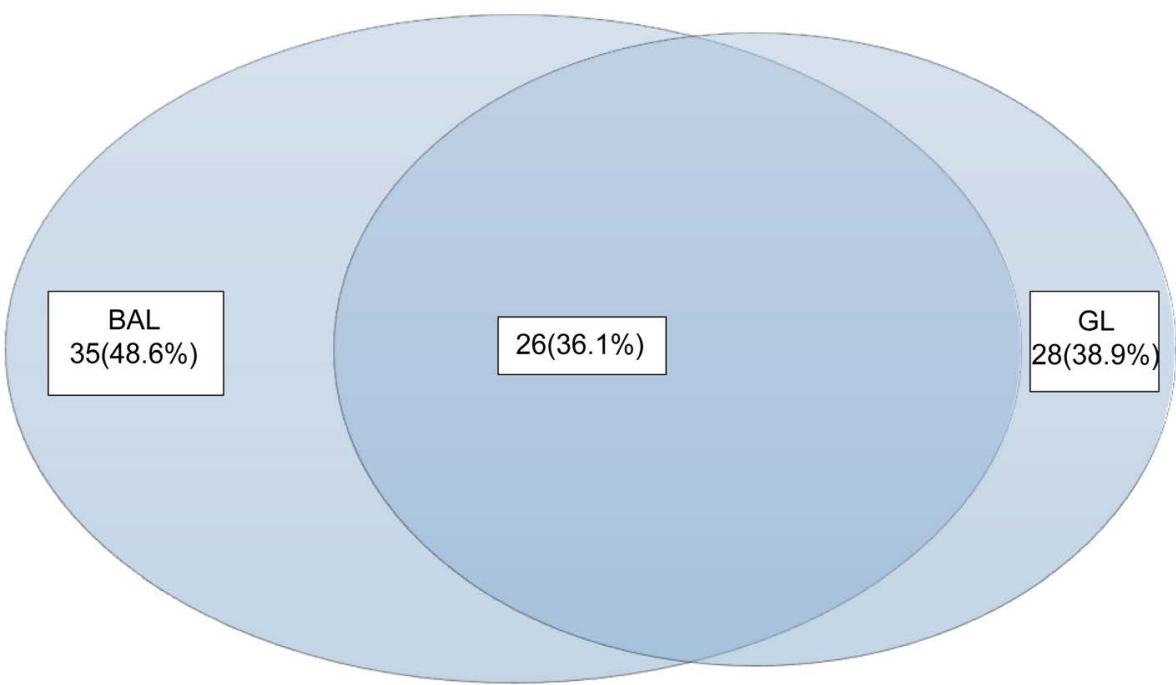

Figure 2. Number of positive GeneXpert MTB/RIF on gastric Lavage (GL) and Broncho alveolar lavage (BAL) specimens.

\section{Discussion}

Results in terms of AFB smear and culture were compared with several other studies on BAL, IS and GL. No direct comparative study on these sampling methods were found to be done on GeneXpert MTB/RIF on adults. It becomes difficult to establish bacteriological diagnosis in patients who are suspected of having pulmonary tuberculosis when they are unable to expectorate. So, we compared the yield of GeneXpert MTB/RIF on the BAL and GA samples. Our study showed difference in yield of the BAL and GL was not statically significant (48.6\% vs. 38.9\%) ( $(\mathrm{p}>0.05$ ). Combine positive results of BAL and/or GL sample were $51.4 \%$ in TB suspect cases. In a study by Singh et al. there was no difference in mycobacterial isolation rates from gastric lavage and BAL when studied in isolation [8]. However, when both GL and BAL were used, these procedures complement each other to increase the diagnostic yield [8] [9].

Most of the studies on GL were done in children. A recently published study by Pang et al., showed $48.6 \%$ sensitivity of GL samples GeneXpert MTB/RIF assay in detecting TB in smear negative children [10]. Previous studies of the GeneXpert that assessed either sputum samples or concentrated decontaminated sputum pellets, have shown test sensitivity of $72 \%-75 \%$ in cases of smear-negative tuberculosis and $98 \%-100 \%$ in cases of smear-positive tuberculosis and specificity 99\% [11]-[15]. Among patients with smear-negative, culture-positive tuberculosis, the addition of a second GeneXpert MTB/RIF test increased sensitivity by $12.6 \%$ and a third by $5.1 \%$, to a total of $90.2 \%$ [16]. Similar study was done in our center on 2001, in which 20 patients were enrolled in the study. Yield of 2 AFB smear and a culture of bronchial washing and GL were compared. Result showed bronchial wash was superior to gastric lavage in culture, but their yield on direct smear was equal [17]. In a comparative study performed by QQ Yin et al. in 250 Chinese children of suspected TB showed Sensitivity of AFB microscopy, MTB culture, and GeneXpert MTB/RIF assay was 8.4\%, 28.9\%, and 53.0\%, respectively. GeneXpert MTB/RIF assay could detect 33.9\% of cases with negative MTB culture, and 48.7\% of cases with negative AFB microscopy [18]. In a prospective study on children by Brown et al. showed culture of gastric lavage had sensitivity only $30 \%$ and induced sputum 39\% [6]. Some studies show yield of 3 induced sputum is superior to 3 GL while others show equal efficacy [19]. 
In our study 3\% patient had Rifampicin resistance. If we had relied solely on sputum smear of the samples, we would have missed those cases and putting them on new treatment regimen could have led to gene amplification to MDR. Another noteworthy factor was the absence of complications due to GL during our study. Notably, it can be compared to major adverse events of bronchoscopy in a study by Dang et al. in which it was stated that this technique is safe as they came across less major complications like pneumothorax [20]. However, the aim of this study was not to evaluate the efficacy of BAL procedure, there were no major complication of bronchoscopy except desaturation, respiratory discomfort during and throat discomfort after the procedure.

In the study, Tuberculosis culture was not done to compare with the outcome of Genexpert, because of resource limitations of the hospital and most patients who present to our (government) setup are poor and cannot pay the cost of the test in private labs. And lastly, our purpose of the study was to evaluate the patient population who are out of reach of culture but have access to GeneXpert facility provided by WHO, which is free of cost.

\section{Conclusion}

In resource poor areas, Gastric lavage can have invaluable role to detect and rule out pulmonary tuberculosis in suspected cases, which are unable to produce sputum. And further, GeneXpert test can be effective to make accurate diagnosis and also detects Rifampicin resistance thereby potentially decreasing morbidity and mortality associated with diagnostic delay, dropout and mistreatment.

\section{Conflict of Interest}

The authors declare that there is no conflict of interest.

\section{References}

[1] World Health Organization (2014) Xpert MTB/RIF Implementation Manual: Technical and Operational "How-To"; Practical Considerations.

[2] World Health Organization (2011) Roadmap for Rolling out Xpert MTB/RIF for Rapid Diagnosis of TB and MDRTB.

[3] Steingart, K.R., Schiller, I., Horne, D.J., Pai, M., Boehme, C.C. and Dendukuri, N. (2014) Xpert(R) MTB/RIF Assay for Pulmonary Tuberculosis and Rifampicin Resistance in Adults. Cochrane Database of Systematic Reviews, $\mathbf{1}$, Cd009593. http://dx.doi.org/10.1002/14651858.cd009593.pub3

[4] World Health Organization (2014) Companion Handbook to the WHO Guidelines for the Programmatic Management of Drug-Resistant Tuberculosis.

[5] Baghaei, P., Tabarsi, P., Farnia, P., Radaei, A.H., Kazempour, M., Faghani, Y.A., Mirsaeidi, M., Novin, A., Chitsaz, E., Mansouri, D. and Masjedi, M.R. (2011) Utility of Gastric Lavage for Diagnosis of Tuberculosis in Patients Who Are Unable to Expectorate Sputum. Journal of Global Infectious Diseases, 3, 339-343.

http://dx.doi.org/10.4103/0974-777X.91054

[6] Brown, M., Varia, H., Bassett, P., Davidson, R.N., Wall, R. and Pasvol, G. (2007) Prospective Study of Sputum Induction, Gastric Washing, and Bronchoalveolar Lavage for the Diagnosis of Pulmonary Tuberculosis in Patients Who Are Unable to Expectorate. Clinical Infectious Diseases, 44, 1415-1420. http://dx.doi.org/10.1086/516782

[7] Larson, J.L., Ridzon, R. and Hannan, M.M. (2001) Sputum Induction versus Fiberoptic Bronchoscopy in the Diagnosis of Tuberculosis. American Journal of Respiratory and Critical Care Medicine, 163, 1279-1280. http://dx.doi.org/10.1164/ajrccm.163.5.1635f

[8] Singh, M., Moosa, N.V., Kumar, L. and Sharma, M. (2000) Role of Gastric Lavage and Broncho-Alveolar Lavage in the Bacteriological Diagnosis of Childhood Pulmonary Tuberculosis. Indian Pediatrics, 37, 947-951.

[9] Dickson, S.J., Brent, A., Davidson, R.N. and Wall, R. (2003) Comparison of Bronchoscopy and Gastric Washings in the Investigation of Smear-Negative Pulmonary Tuberculosis. Clinical Infectious Diseases, 37, 1649-1653. http://dx.doi.org/10.1086/379716

[10] Pang, Y., Wang, Y., Zhao, S., Liu, J., Zhao, Y. and Li, H. (2014) Evaluation of the Xpert MTB/RIF Assay in Gastric Lavage Aspirates for Diagnosis of Smear-Negative Childhood Pulmonary Tuberculosis. Pediatrics Infectious Disease Journal, 33, 1047-1051. http://dx.doi.org/10.1097/INF.0000000000000403

[11] Helb, D., Jones, M., Story, E., Boehme, C., Wallace, E., Ho, K., Kop, J., Owens, M.R., Rodgers, R., Banada, P., Safi, H., Blakemore, R., Lan, N.T., Jones-Lopez, E.C., Levi, M., Burday, M., Ayakaka, I., Mugerwa, R.D., McMillan, B., Winn-Deen, E., Christel, L., Dailey, P., Perkins, M.D., Persing, D.H. and Alland, D. (2010) Rapid Detection of Mycobacterium tuberculosis and Rifampin Resistance by Use of On-Demand, Near-Patient Technology. Journal of Clinical 
Microbiology, 48, 229-237. http://dx.doi.org/10.1128/JCM.01463-09

[12] Boehme, C.C., Nabeta, P., Hillemann, D., Nicol, M.P., Shenai, S., Krapp, F., Allen, J., Tahirli, R., Blakemore, R., Rustomjee, R., Milovic, A., Jones, M., O’Brien, S.M., Persing, D.H., Ruesch-Gerdes, S., Gotuzzo, E., Rodrigues, C., Alland, D. and Perkins, M.D. (2010) Rapid Molecular Detection of Tuberculosis and Rifampin Resistance. New England Journal of Medicine, 363, 1005-1015. http://dx.doi.org/10.1056/NEJMoa0907847

[13] Marlowe, E.M., Novak-Weekley, S.M., Cumpio, J., Sharp, S.E., Momeny, M.A., Babst, A., Carlson, J.S., Kawamura, M. and Pandori, M. (2011) Evaluation of the Cepheid Xpert MTB/RIF Assay for Direct Detection of Mycobacterium tuberculosis Complex in Respiratory Specimens. Journal of Clinical Microbiology, 49, 1621-1623. http://dx.doi.org/10.1128/JCM.02214-10

[14] Armand, S., Vanhuls, P., Delcroix, G., Courcol, R. and Lemaitre, N. (2011) Comparison of the Xpert MTB/RIF Test with an IS6110-TaqMan Real-Time PCR Assay for Direct Detection of Mycobacterium tuberculosis in Respiratory and Nonrespiratory Specimens. Journal of Clinical Microbiology, 49, 1772-1776. http://dx.doi.org/10.1128/JCM.02157-10

[15] Moure, R., Munoz, L., Torres, M., Santin, M., Martin, R. and Alcaide, F. (2011) Rapid Detection of Mycobacterium tuberculosis Complex and Rifampin Resistance in Smear-Negative Clinical Samples by Use of an Integrated RealTime PCR Method. Journal of Clinical Microbiology, 49, 1137-1139. http://dx.doi.org/10.1128/JCM.01831-10

[16] Boehme, C.C., Nicol, M.P., Nabeta, P., Michael, J.S., Gotuzzo, E., Tahirli, R., Gler, M.T., Blakemore, R., Worodria, W. and Gray, C. (2011) Feasibility, Diagnostic Accuracy, and Effectiveness of Decentralised Use of the Xpert MTB/ RIF Test for Diagnosis of Tuberculosis and Multidrug Resistance: A Multicentre Implementation Study. The Lancet, 377, 1495-1505. http://dx.doi.org/10.1016/S0140-6736(11)60438-8

[17] Rizvi, N., Rao, N.A. and Hussain, M. (2000) Yield of Gastric Lavage and Bronchial Wash in Pulmonary Tuberculosis. The International Journal of Tuberculosis and Lung Disease, 4, 147-151.

[18] Yin, Q.-Q., Diagnosis, W.-W. Jiao, R., Han, A.-X., Jiao, L., Sun, J.-L., Tian, Y.-Y., Ma, X.-C., Rao, C., Shen, A.D. and Li, Q.-J. (2014) Rapid of Childhood Pulmonary Tuberculosis by Xpert MTB/RIF Assay Using Bronchoalveolar Lavage Fluid. BioMed Research International. http://dx.doi.org/10.1155/2014/310194

[19] Hatherill, M., Hawkridge, T., Zar, H.J., Whitelaw, A., Tameris, M., Workman, L., Geiter, L., Hanekom, W.A. and Hussey, G. (2009) Induced Sputum or Gastric Lavage for Community-Based Diagnosis of Childhood Pulmonary Tuberculosis? Archives of Disease in Childhood, 94, 195-201. http://dx.doi.org/10.1136/adc.2007.136929

[20] Dang, D., Robinson, P.C., Winnicki, S. and Jersmann, H.P. (2012) The Safety of Flexible Fibre-Optic Bronchoscopy and Proceduralist-Administered Sedation: A Tertiary Referral Centre Experience. Internal Medicine Journal, 42, 300305. http://dx.doi.org/10.1111/j.1445-5994.2010.02261.x

\section{Submit or recommend next manuscript to SCIRP and we will provide best service for you:}

Accepting pre-submission inquiries through Email, Facebook, LinkedIn, Twitter, etc.

A wide selection of journals (inclusive of 9 subjects, more than 200 journals)

Providing 24-hour high-quality service

User-friendly online submission system

Fair and swift peer-review system

Efficient typesetting and proofreading procedure

Display of the result of downloads and visits, as well as the number of cited articles

Maximum dissemination of your research work

Submit your manuscript at: http://papersubmission.scirp.org/ 